Jurnal geoedusains, Volume 1, Nomor 2, Desember 2020

\title{
Integrasi Nilai-Nilai Kearifan Lokal Joka'ju Masyarakat Nggela dalam Membangun Karakter Sadar Bencana Siswa di Sekolah Menengah Atas
}

\author{
Sunimbar ${ }^{1 *}$, Natalia Adel H. N. Mari ${ }^{2}$ \\ ${ }^{1,2}$ Program Studi Pendidikan Geografi Universitas Nusa Cendana
}

Korespondensi: *imbarsunimbar@gmail.com

\begin{abstract}
Abstrak
Desa Nggela yang berada dalam wilayah administrasi kabupaten ende merupakan salah satu desa di kecamatan wolojita yang rentan terhadap bencana geologi yaitu tanah longsor. Upaya mitigasi untuk meningkatkan kesadaran masyarakat dalam menghadapi bencana dapat dilakukan melalui pendidikan kepada peserta didik di desa Nggela. Pendidikan sebagai upaya sadar manusia dalam memahami diri sendiri dan lingkungannya atau upaya manusia dalam memahami interaksi antara makro dan mikro kosmos. Penelitian ini difokuskan sebagai upaya untuk memperoleh penjelasan mengenai integrasi nilai-nilai kearifan lokal masyarakat desa Nggela dalam upacara adat joka ju sebagai pembentukan karakter peserta didik dalam membangun perilaku sadar bencana di kalangan pelajar. Jenis penelitian ini adalah penelitian kualitatif yang bersifat studi pustaka dengan pendekatan analisis deskriptif untuk menghasilkan informasi berupa catatan dan data deskriptif yang terdapat pada sumber referensi atau literatur. Upacara adat joka ju yang dilakukan setahun sekali untuk memperingati tahun baru menurut adat setempat dengan tujuan tolak bala atau yang dikenal dengan mengusir roh jahat dan sebagai upaya memohon kepada Tuhan agar terhindar dari bala bencana. Upacara ini merupakan tradisi dan budaya bangsa Indonesia, khususnya masyrakat yang berada di pulau Flores, Kabupaten Ende Desa Nggela Suku Lio. Ritual ini dipandang sebagai salah satu yang benar yang di amanatakan oleh pendahulu sebelumnya. Nilai sosial inilah yang dapat di integrasikan sebagai upaya sadar bencana bagi pelajar di desa nggela dimana sekolah berkewajiban membekali peserta didik dengan pendidikan baik secara teoritis (berkaitan dengan ilmu pengetahuan dan teknologi) maupun non teoritis (berkaitan dengan pembentukan moral dan budi pekerti). Kata Kunci: Kearifan lokal, Joka ju, Pendidkan sadar bencana, Nggela
\end{abstract}

\section{Integration Of Values Of Local Joka'ju Of Nggela Community In Building Disaster Awareness Characters Of Students In The High School}

\begin{abstract}
Nggela Village, which is in the administrative area of Ende Regency, is one of the villages in the Wolojita sub-district which is prone to geological disasters, namely landslides. Mitigation efforts to increase public awareness in dealing with disasters can be done through education to students in Nggela village. Education is a conscious human effort in understanding themselves and their environment, or human efforts in understanding the interactions between the macro and micro cosmos. This research is focused as an effort to obtain an explanation of the integration of the values of local wisdom of the Nggela village community in the traditional Joka'Juceremony as a
\end{abstract}

Integrasi Nilai-Nilai Kearifan Lokal Joka'ju...

Sunimbar, Natalia Adel H. N. Mari

62 
character formation of students in building disaster awareness behavior among students. The type of research is qualitative research particularly literature study with a descriptive analysis approach to produce information in the form of notes and descriptive data found in reference sources or literature. The traditional Joka'Juceremony which is carried out once a year to commemorate the new year according to local customs with the aim of repelling the bala or what is known as driving out evil spirits and as an effort to ask God to avoid disaster. This ceremony is a tradition and culture of the Indonesian people, especially the people on the Flores island, Ende Regency, Nggela Village, Lio tribe. This ritual is seen as one of the correct ones that was stated by its previous predecessors. This social value can be integrated as a disaster awareness effort for students in Nggela village where schools are obliged to equip students with education both theoretically (related to science and technology) and non-theoretically (relating to the formation of morals and character).

Key words: local wisdom, Joka'Ju, Disaster-aware education, Nggela

\section{Pendahuluan}

Secara astronomis Pulau Flores terletak pada garis lintang selatan $8^{\circ} 4^{\prime}$ dan $8^{\circ} 58^{\prime}$ dan terletak di antara garis bujur timur $119^{\circ} 48^{\prime}$ dan $123^{\circ} 1^{\prime} 30^{\prime}$ memiliki luas wilayah sekitar 14.300 km², dengan puncak tertinggi adalah Gunung Ranakah (2350 meter) berada dalam busur gunung api atau yang lebih dikenal dengan busur banda yang terhampar dari pulau Bali pulau Lombok, pulau Sumbawa dan pulau-pulau kecil di bagian timur flores sampai ambon. Secara tektonik busur vulkanik ini merupakan hasil penujaman lempeng benua Australia ke arah utara terhadap lempeng benua Eurasia dan penujaman antara lempeng samudera hindia terhadap lempeng benua Eurasia (padmawijaja, 2010).

Sebagai wilayah yang berada dalam busur banda dalam tidak dapat dipungkiri wilayah pulau Flores sering mengalami bencana geologi, seperti gempa bumi, letusan gunung berapi, tanah longsor dan tsunami. Kabupaten Ende yang berada di Pulau Flores dengan luas wilayah $260,127 \mathrm{~km}^{2}$ juga seringkali dilanda oleh bencana alam. Pada tahun 1939 curah hujan tinggi memicu terjadinya tanah longsor dan banjir serta menghancurkan sejumlah besar rumah-rumah penduduk, Pada tahun 1961 gempa bumi merusak sejumlah besar rumah-rumah penduduk di seluruh pulau flores, termasuk Ende, Pada tahun 1969 gunung lya meletus menyebabkan korban jiwa dan hilangnya harta benda masyarakat. Sebanyak 177 rumah penduduk, 6 bangunan masjid, dan 3 sekolah runtuh, dan sejumlah bangunan lain rusak berat. Pada tahun 1988 curah hujan yang tinggi telah memicu banjir, longsor dan aliran rombakan. Banjir Integrasi Nilai-Nilai Kearifan Lokal Joka'ju... 
disertai potongan kayu/batu tersebut menghancurkan hampir keseluruhan desa Rowo Reke dan menelan korban jiwa 48 orang. Banjir bandang disertai potongan kayu/batu mengancurkansebagian dari desa Aeisa yang terletak $2 \mathrm{~km}$ sebelah barat laut Ende. Akses jalan antara Ende dan Detusoko tertutup di 11 titik akibat longsor dan aliran rombakan tersebut. Pada tahun 1992 gempa bumi dan tsunami yang berpusat di kabupaten Sikka telah menghancurkan sebagai besar wilayah kabupaten ende. Pada tahun 2003 curah hujan yang tinggi telah memicu terjadinya banjir bandang (flashflood), longsor dan aliran rombakan di Kabupaten Ende, sementara bandar udara dan pelabuhan tidak dapat digunakan. Sebagian besar desa Ndungga (Detumbawa) telah dihancurkan oleh banjir disertai potongan kayu/batu, dan mengambil nyawa 27 warga desa (Georisk Project, Badan Geologi, 2009).

Desa Nggela yang berada dalam wilayah administrasi Kabupaten Ende merupakan salah satu desa di kecamatan Wolojita yang rentan terhadap bencana geologi yaitu tanah longsor. Berada pada ketinggian $188 \mathrm{mdpl}$ dengan tingkat kemiringan lereng diatas $40 \%$. Jenis tanah yang mendominasi wilayah dese Ngggela adalah tanah mediteran dengan bentuk wilayah volcano, dengan tekstur tanah yang terdiri atas 22,99\%, tekstur tanah sedang, 57,11\% tekstur tanah kasar, 3,70 \% tekstur tanah halus dan sisanya sebesar $16,90 \%$ tidak dikategorikan. Berdasarkan kondisi geologisnya, wilayah ini sangat rentan terjadi bencana. Sehingga dibutuhkan kesadaran masyarakat tentang memitigasi bencana. Pendidikan sadar bencana kepada peserta didik di desa merupakan salah satu upaya menumbuhkan kesadaran masyarakat dalam menghadapi bencana (BPS Kab. Ende, 2019).

Pendidikan sebagai upaya sadar manusia dalam memahami diri sendiri dan lingkungannya atau upaya manusia dalam memahami interaksi antara makro dan mikro kosmos. Oleh sebab itu pendidikan harus mampu memupuk dan menumbuhkan kesadaran akan arti keberadaan manusia untuk lingkungan dan alam sekitar. Pendidikan berbasis kearifan lokal lebih didasarkan kepada pengayaan nilai-nilai cultural. Pendidikan ini mengajarkan peserta didik untuk selalu dekat dengan situasi konkrit yang mereka hadapi sehari-hari. Dengan kata lain model pendidikan ini mengajak kepada kita semua untuk selalu dekat dan menjaga keadaan sekitar yang bersifat nilai yang berada di dalam lokal masayarakat tersebut. 
Kearifan lokal masyarakat Nggela dalam Upacara Joka'Ju merupaka tradisi yang telah di turunkan dari generasi ke generasi. Kata Joka'Ju merupakan kata majemuk berasal dari kata Joka: tolak dan $J u$ : bala/segala roh jahat. Ritual tersebut memiliki dua tujuan yaitu Pertama agar masyarakat setempat tidak "Pelapani" (tidak berbuat jahat); Kedua sebagai upaya untuk menolak segala bentuk bencana yang terjadi di wilayah Nggela. Di sisi lain upacara tersebut juga dilaksanakan untuk merayakan tahun baru menurut adat penduduk setempat. Keterikatan masyarakat Nggela dengan alam sangat terasa dalam pelaksanaan upacara joka ju, dimana perilaku keseharian masyarakat banyak di pengaruhi oleh alam pikiran yang bersifat spiritual. Masyarakat Nggela dalam kehidupan sehari-hari memiliki hubungan istimewa dengan alam serta di kenal juga sebagai masyarakat yang menjunjung nilai tradisi yang bertujuan untuk menjaga kerukunan, keselamatan, dan bentuk syukur kepada Tuhan. Nilai- nilai inilah yang dapat membentuk perilaku peserta didik dalam berinteraksi dengan alam sebagai upaya sadar bencana sejak dini (Supriyadin, 2016).

\section{Metode}

Jenis penelitian ini adalah penelitian kualitatif yang bersifat studi pustaka dengan pendekatan analisis deskriptif untuk menghasilkan informasi berupa catatan dan data deskriptif yang terdapat pada sumber referensi atau literatur. Pada penelitian ini dilakukan pengkajian mengenai konsep dan teori yang digunakan berdasarkan literatur yang tersedia seperti pada artikel dan buku yang relevan dalam pengelolaan lingkungan oleh masyarakat. Penelitian ini difokuskan sebagai upaya untuk memperoleh penjelasan mengenai integrasi nilai-nilai kearifan lokal masyarakat desa Nggela dalam upacara adat joka ju sebagai pembentukan karakter peserta didik dalam membangun perilaku sadar bencana di kalangan pelajar (Moleong,2010).

\section{Hasil dan Pembahasan}

Kearifan Lokal Ritual Joka'JuMasyarakat Nggela

Upacara adat joka ju yang dilakukan setahun sekali untuk memperingati tahun baru menurut adat setempat dengan tujuan tolak bala atau yang dikenal dengan mengusir roh jahat dan sebagai upaya memohon kepada Tuhan agar terhindar dari 
bala bencana. Upacara ini merupakan tradisi dan budaya bangsa Indonesia, khususnya masyarakat Suku Lio Desa Nggela yang berada Kabupaten Ende, Nusa Tenggara Timur. Pada dasarnya Joka'Ju merupakan ritual yang bernilai sakral dan bertujuan sangat mulia. Karena didalam ritual adat tersebut mengajarkan masyarakat setempat untuk bisa saling menghargai antara manusia, tumbuhan, hewan, dan tanah untuk tidak saling atau terus melukai.

Satu hari sebelum upacara dilaksanakan, masyarakat harus menangkap ayam, babi, dan kambing yang berkeliaran dan para pemilik tidak boleh marah atau melarang. Masyarakat diwajibkan menangkap babi dan kambing lebih dari satu. Selain itu ada Mosalaki yang bertugas meminta beras dari rumah ke rumah. Pada malam hari masyarakat setempat melakukan upacara memberi makan leluhur berupa hasil tangkapan binatang yang dilakukan pada sore harinya. Persembahan tersebut diantar oleh para Mosalaki yang dilakukan dengan berjalan kaki dari arah utara ke selatan atau dari gunung ke pantai. Pada saat upacara berlangsung, masyarakat setempat harus membunyikan gong atau segala sesuatu yang bisa dibunyikan, hingga para mosalaki kembali ke rumah. Alunan bunyi gong berbunyi itulah tanda upacara adat Joka'Ju telah dimulai.

Tahap pertama upacara adalah memberi makan kepada leluhur, dan masyarakat menunggu hari berikutnya untuk melaksanakan upacara Joka'Ju. Prosesi joka'ju inilah yang dianggap sakral karena selama empat hari berturut-turut masyarakat Nggela tidak boleh melakukan segala aktivitas seperti, berkebun, menyalakan api diluar rumah, memetik tumbuhan yang sedang tumbuh, berkelahi, bahkan mengubur orang mati. Mereka hanya dibolehkan untuk bersenang-senang. Masyarakat yang melanggar larangan tersebut akan mendapat hukuman. Hukuman digolongkan menjadi dua, yakni hukuman besar dan hukuman kecil. Hukuman besar misalnya perkelahian atau apabila ada orang meninggal tidak boleh melakukan penggalian tanah; dan denda yang diberikan berupa satu ekor babi dengan berat dua orang pikul atau senilai dua juta rupiah. Sedangkan hukuman kecil berupa, menyalakan api, berkebun, dan memetik tumbuhan, denda yang diberikan berupa moke (minuman khas daerah flores) ,uang, dan beras. 
Tahap terakhir dari rangkaian ritual ini adalah perayaan dimana tergambar ciri khas masyarakat tradisional berkomunikasi dengan Tuhan bukan dengan doa tapi perayaan. Berawal dari rumah adat Pemimpin adat/Mosalaki (Sa'o Ria) dimana salah satu dari tiga Mosalaki yang tinggal dalam rumah adat ini memberi pengumuman tentang kapan ritual ini akan dilaksanakan. Keesokkan harinya, ketujuh Mosalaki pergi ke Penga lu (sebuah karang di tepi pantai sebelah selatan permukiman adat). Sebelumnya mereka memasang sebuah tanda larangan berupa bambu beranting di sebelah utara dan selatan permukiman adat, sebuah rumah-rumahan di atas Kanga Ria sebagai persembahan kepada sang pencipta. Setelah itu mosalaki ke Penga lu membuat persembahan dan melepas semua bala bencana dibuang ke arah laut. Setelah itu ketujuh mosalaki ini kembali ke permukiman saat hari mulai gelap agar semua hal buruk yang telah dibuang tidak kembali mengikuti mereka kembali ke desa.

Setelah sampai di permukiman seorang anak diikat di dalam Sa'o Ria, dan ketujuh Mosalaki mulai melakukan perarakan mulai dari selatan kampung, lalu ke arah timur dan utara, dan dari utara ke barat dan kembali ke selatan. Sepanjang prosesi ini semua masyarakat memukul bagian-bagian dari rumah yaitu dinding, lantai atau barangbarang lain sebagai bunyi-bunyian sambil mengeluarkan kata-kata yang buruk kepada kedua anak yang diikat. Hal ini guna menunjukkan kepada semua hal buruk dan bala bencana sampai pada roh-roh jahat bahwa anak dari masyarakat desa sendiri diperlakukan seperti itu kalau berbuat jahat, apalagi untuk kepada hal-hal buruk lainnya. Setelah itu ketujuh Mosalaki kembali ke Sa'o Ria untuk makan bersama dan kemudian bubar.

Setelah prosesi tersebut, empat hari kemudian semua masyarakat desa tidak diperbolehkan bekerja dan hanya berpesta dan bersuka ria. Masyarakat dari desa lain tidak diperbolekan masuk ke dalam permukiman begitu juga sebaliknya masyarakat desa Nggela dilarang keluar desa. Apabila melanggar akan dikenakan sangsi adat. Hal ini untuk menunjukkan rasa syukur kepada Sang Pencipta dan para leluhur atas panen yang diperoleh tahun ini. Ritual Joka Ju dilaksanakan mulai dari permukiman adat, Pantai Penga lu dan kembali lagi ke permukiman adat. Puse Nua, Kanga Ria, Tubumusu, dan Keda merupakan elemen sakral dalam permukiman adat, namun dalam ritual adat ini dilakukan di atas Kanga Ria sebagai tempat untuk menaruh persembahan 
kepada sang pencipta dengan menaruh rumah-rumah di atasnya. Posisi keempat elemen ini berada di tengah-tengah permukiman yang menunjukkan keempat elemen ini sakral sehingga prosesi ritual ini dilakukan di luar dari zona sakral tersebut.

\section{Integrasi Nilai-Nilai Kearifan Lokal dalam Pembelajaran di Sekolah Menengah Atas}

Setiap aktivitas budaya memiliki nilai-nilai yang tersirat didalam pelaksanaannya. Entah di sadari atau tidak nilai dari suatu tradisi akan terus ada selama kebudayaan itu dipelihara. Nilai adalah keyakinan preferensi ataupun asumsi mengenai apa yang diinginkan atau dianggap baik oleh manusia. Nilai pada hakikatnya mengarahkan perilaku dan pertimbangan seseorang, tetapi ia tidak menghakimi apakah sebuah perilaku tertentu salah atau benar. Masyarakat sebagai komunitas yang terdiri dari individu-individu dengan berbagai macam aktivitas sosialnya sehingga terbentuklah nilai sosial dalam kehidupan bermasyarakat tersebut. Nilai sosial merupakan sikap dan ungkapan perasaan masyarakat untuk menentukan apa yang dianggap benar dan salah. Ritual joka' ju merupakan sebuah ritual adat yang dianggap baik oleh masyarakat Nggela karena dalam pelakasanaannya masyarakat dapat berinteraksi satu sama lain dan saling mendukung untuk keselamatan dan kemajuan bersama. Hal ini di perkuat oleh tokoh masyarakat desa Nggela yang menyatakan bahwa tradisi ini sudah dijalakan selam turun temurun oleh mosalaki bersama masyarakat. Jika ritual joka ju ini tidak di laksanakan maka mosalaki bersama masyarakat nggela akan mendapatkan bala bencana seperti kekeringan, tanah longsor, dan bencana alam lainnya. Ritual ini dipandang sebagai salah satu yang benar yang diamanatkan oleh pendahulu. Nilai sosial inilah yang dapat di integrasikan sebagai upaya sadar bencana bagi pelajar di desa nggela dimana sekolah berkewajiban membekali peserta didik dengan pendidikan baik secara teoritis (berkaitan dengan ilmu pengetahuan dan teknologi) maupun non teoritis (berkaitan dengan pembentukan moral dan budi pekerti).

Peserta didik Sekolah Menengah Atas (SMA) secara umum berusia enam belas tahun sampai dengan Sembilan belas tahun dan berapa pada tahap perkembangan remaja. Masa remaja merupakan masa transisi perkembangan antara masa kanak kanak dan masa dewasa yang mengandung perubahan besar pada kondisi fisik, kognitif dan psikososial. Remaja sering berpikir tentang kemungkinan-kemungkinan 
yang dapat terjadi. Mereka berpikir tentang ciri-ciri ideal diri mereka sendiri, orang lain, dan dunia. Karakteristik siswa SMA harus mampu berpikir kritis dan kreatif untuk memecahkan permasalahan dan membandingkan kenyataan yang terjadi dengan standar pemikiran rasionalnya (Istianah, 2013).

Pembelajaran di SMA dengan penerapan kurikulum 2013 diharapkan mampu untuk mempersiapkan manusia Indonesia agar memiliki kemampuan hidup sebagai pribadi dan warga negara yang beriman, produktif, kreatif, inovatif, dan afektif serta mampu memberikan peran aktif pada kehidupan bermasyarakat, berbangsa, bernegara, dan peradaban dunia. Kurikulum 2013 adalah Kurikulum yang mengutamakan pada pemahaman, skill, dan pendidikan berkarakter. Oleh karena itu, pada masa SMA sangat penting untuk memantapkan karakter peserta didik untuk berpikir lebih kritis terhadap kondisi lingkungan disekitarnya dan diaplikasikan dengan tindakan sebagai bentuk kesadaran akan bencana yang dapat terjadi disekitarnya melalui kebiasaan-kebiasaan yang ada di masyarakat secara arif dan bijaksana. Penggalian kearifan lokal sebagai konten pembentukan karakter peseta didik yang nantinya bisa disisipkan dalam pembelajaran yang merupakan upaya revalitasi kearifan lokal, sehingga peserta didik menghayatinya karena itu tidak lepas dan tidak jauh dari budaya mereka (Anwar, 2013).

Hadi, dkk (2016) menyatakan pembelajaran menggunakan lingkungan sebagai objek belajar adalah solusi yang dapat mengarahkan peserta didik pada upaya mengaitkan pelajaran akademis dengan konteks kehidupan nyata. Lebih lanjut Hadi menyatakan bahwa sekolah juga dapat berfungsi mentransmisi dan mentransformasi kearifan lokal yang terwujud dalam bentuk kebudayaan menjadi sumber belajar. Hal ini didukung dengan masuknya materi kearifan lokal dalam kurikulum 2013 yang dikeluarkan oleh menteri pendidikan. Bentuk dan tindakan yang dilakukan oleh masyarakat Nggela dalam melakukan ritual joka ju terbukti dapat mencegah terjadinya bencana alam khususnya kekeringan dan banjir dengan melihat keadaan topografi wilayah kecamatan wolojita khusnya Desa Nggela. Dari ritual yang di lakukan oleh masyarakat Nggela menunjukkan bahwa kearifan lokal tersebut dapat di jadikan materi pembelajaran akan pentingnya kesadaran peserta didik untuk menjaga lingkungan 
sekitarnya. Nilai dari setiap tahapan pada ritual joka ju dapat di jadikan sumber pelajaran dari tiap mata pelajaran yang di ajarkan.

Proses integrasi nilai-nilai kearifan lokal masyarakat Nggela dalam pendidikan karakter Sekolah Menengah Atas di Kabupaten Ende secara umum dan pada sekolah yang berada di kecamatan Wolojita dapat dilakukan untuk beberapa bidang studi seperti Geografi dan Sosiologi. Pengintegrasian nilai-nilai kearifan lokal masyarakat Nggela misalnya pola pengelolaan hutan untuk menjaga sumber daya alam di kawasan taman nasional kelimutu kerena kecamatan Wolojita merupakan kecamatan penyangga untuk TNK. Guru dalam pembelajaran dapat memanfaatkan tema "kearifan lokal" dalam mencegah terjadinya bencana banjir atau longsor. Pada Mata pelajaran Geografi pada kelas X KD 3.7 tentang menganalisis jenis dan penanggulangan bencana alam melalui edukasi, kearifan lokal, dan pemanfaatan teknologi modern. Contoh pengintegrasian nilai kearifan lokal masyarakat Nggela yaitu dalam melakukan ritual joka ju sebagai bentuk permohonan pada yang kuasa untuk terhindar dari bala bencana. Ritual ini menggunakan pendekatan lingkungan yang melibatkan manusia dan alam dalam pelaksanaanya.

Pada mata pelajaran Sosiologi pada kelas XII KD. 3.4 memiliki pengetahuan bagaimana melakukan strategi pemberdayaan komunitas dengan mengedepankan nilai-nilai kearifan lokal di tengah-tengah pengaruh globalisasi. Pada kompetensi dasar ini strategis masyarakat Nggela dalam mempertahankan nilai-nilai kearifan lokal terlihat dalam upaya terus melestarikan ritual joka ju hingga saat ini. Ritual ini dipertahankan dan dilestarikan dengan tujuan mempertahankan aturan-aturan adat yang menjadikan kehidupan masyarakat menjadi sejahtera dan secara arif dalam menjaga interaksi antara manusia dan alam.

\section{Simpulan dan Saran}

Bencana tanah longsor yang terjadi di beberapa wilayah Kabupaten Ende menjadi perhatian bagi seluruh masyarakat. Kurangnya perhatian masyarakat terhadap kualitas lingkungannya menjadikan bencana tersebut belum dapat diminimalisir. Masyarakat Kecamatan Wolojita yang hidup berdampingan dengan Hutan, salah satunya yaitu Masyarakat Adat Nggela yang memiliki pengetahuan secara turun 
temurun dalam mengkonservasi alam. Kearifan lokal masyarakat Ngegela dalan Ritual Joka Ju ditanamkan pada diri siswa di tingkat Sekolah Menengah Atas. Karakteristik siswa SMA mampu berpikir secara rasional dan dapat memecahkan masalah disekitarnya. Pengintegrasian nilai-nilai kearifan lokal Joka Ju pada masyarakat Nggela untuk membangun karakter sadar bencana siswa dapat diterapkan pada mata pelajaran geografi 3.1, pada kelas XI KD. 3.3 dan KD. 3.7 dan pelajaran sosiologi pada kelas XII KD. 3.4. Pengintegrasian pendidikan karakter sadar bencana dengan kearifan lokal masyarakat Adat Nggela dalam ritual Joka Ju yang dilakukan di Sekolah Menengah Atas di Kabupaten Ende diharapkan siswa pada masa kini dan akan datang mampu mengurangi bencana alam seperti banjir, banjir bandang, dan tanah longsor.

\section{Daftar Pustaka}

Anwar, H. S, 2013. Membangun Karakter Bangsa. At-Ta'dib, 8(1), 1-17. https://doi.org/10.21111/AT-TADIB.V8I1.511

BPS Kab Ende, 2019. Kecamatan Wolojita. Badan Pusat Statistik Kabupaten Ende.

Georisk Project, Badan Geologi, 2009. Kerjasama Indonesia-Jerman dalam Analisis Bahaya Geologi dan Risiko Kabupaten Ende Propinsi Nusa Tenggara Timur.

Hadi, S, 2016. Menggagas Pendidikan Karakter Responsif Gender. Palastren, 8(2), 243-270.

ISBN 978- 602-9105-19-3.Edisi Pertama. Bandung. h.1 - 23.

Istianah, E, 2013. Meningkatkan Kemampuan Berpikir Kritis Dan Kreatif Matematik Dengan Pendekatan Model Eliciting Activities (Meas) Pada Siswa Sma. Infinity Journal, 2(1), 43. https://doi.org/10.22460/infinity.v2i1.23

Moleong, L. J. 2007. Metode Penelitian Kualitatif. Bandung: Remaja Rosdakarya.

P. Supriyadin, U, 2016. Padangan Masyarakat Trehadap Ritual Joka Ju Pada Masyarakat Desa Mbuliwaralau Kecamatan Wolowaru Kabupaten Ende. Universitas Flores, Ende.

Padmawijaja, T, 2010. Kondisi geologi daerah ruuteng di tafsir pada gaya berat" JSDG vol. 20, no 5, Oktober.

Integrasi Nilai-Nilai Kearifan Lokal Joka'ju...

Sunimbar, Natalia Adel H. N. Mari 